ARTIGO

d. $10.22481 /$ praxisedu.v15i33.5305

\title{
PARA PENSAR E MOVIMENTAR A FORMAÇÃO DOCENTE NA EJA: UM MAPEAMENTO DAS PRODUÇÕES ACADÊMICAS ENTRE O PERÍODO 2015-2016
}

\author{
TO THINK AND MOVING TEACHER TRAINING IN THE EJA: A MAPPING OF \\ ACADEMIC PRODUCTIONS BETWEEN THE 2015-2016 PERIOD
}

PARA PENSAR Y MOVIMIENDAR LA FORMACIÓN DOCENTE EN LA EJA: UN
MAPA DE LAS PRODUCCIONES ACADÉMICAS ENTRE EL PERÍODO 2015-2016

Suelen Santos Mauricio

Universidade do Estado de Santa Catarina - Brasil

Luiz Martins Júnior

Universidade do Estado de Santa Catarina - Brasil

Rosa Elisabete Militz W. Martins

Universidade do Estado de Santa Catarina - Brasil

\begin{abstract}
Resumo: O presente trabalho busca refletir a respeito da formação docente na modalidade da Educação de Jovens e Adultos (EJA). Para fornecer maiores subsídios a discussão, realizamos um levantamento de trabalhos através do banco de dissertações e teses da Capes online seguindo os seguintes critérios de pesquisa; dissertações e teses apresentadas nos anos de 2015 e 2016 no Brasil, com sua área de concentração na Educação, em Programas de Pós-graduação em Educação, que possuem as temáticas "formação de professores" e "EJA". A partir das leituras estabelecemos eixos de convergência entre os trabalhos para aprofundamento da discussão. Foram analisados o total de nove dissertações e duas teses. Conclui-se que a formação de professores destinada a EJA é uma área incipiente e em construção, tanto em pesquisas acadêmicas quanto em políticas públicas, educacionais e na realidade das salas de aula dos cursos de licenciatura.
\end{abstract}

Palavras-chave: Educação de Jovens e Adultos. Formação de professores. Formação inicial.

Abstract: The present work seeks to reflect on teacher education in the modality of Youth and Adult Education (EJA). To provide further subsidies to the discussion, we conducted a survey of works through the thesis and dissertation bank of Capes online following the following research criteria; dissertations and theses presented in the years 2015 and 2016 in Brazil, with its area of concentration in Education, in Post-Graduate Programs in Education, which have the themes "teacher training" and "YAE". From the readings we establish axes of convergence between the works to deepen the 
discussion. A total of nine dissertations and two theses were analyzed. It is concluded that teacher training for the EJA is an incipient area and under construction, both in academic research and in public policies, educational and in the reality of the classrooms of undergraduate courses.

Keywords: Teacher training; Initial formation; Youth and Adult Education.

Resumen: El presente trabajo busca reflexionar sobre la formación docente en la modalidad de la Educación de Jóvenes y Adultos (EJA). Para proporcionar mayores subsidios a discusión, realizamos un levantamiento de trabajos a través del banco de disertaciones y tesis de Capes online siguiendo los siguientes criterios de investigación; en el marco de los programas de postgrado en Educación, que poseen las temáticas "formación de profesores" y "EJA". A partir de las lecturas establecimos ejes de convergencia entre los trabajos para profundizar la discusión. Se analizaron el total de nueve disertaciones y dos tesis. Se concluye que la formación de profesores destinada a EJA es un área incipiente y en construcción, tanto en investigaciones académicas como en políticas públicas, educativas y en la realidad de las aulas de los cursos de licenciatura.

Palabras clave: Educación de Jóvenes y Adultos. Formación de profesores. Formación inicial.

\section{Considerações introdutórias}

A Educação de Jovens e Adultos (EJA) é uma modalidade de ensino da Educação Básica que possui diretrizes e normativas próprias devido suas particularidades e especificidades que lhe conferem importantes e profundos diferenciais em relação às demais modalidades (Educação Infantil, Ensino Fundamental, Ensino Médio e Educação Especial).

Dentre tais especificidades estão o perfil dos alunos: trabalhadores, oriundos das periferias e do campo (ALTHOF; MARTINS FILHO, 2016), com diferentes trajetórias, que carregam consigo experiências de vida que os diferenciam das crianças que compõem o alunado da Educação infantil e do ensino fundamental. Além disso, tais sujeitos vivenciaram a exclusão da escola na "idade própria".

Outro diferencial é a diversidade dos sujeitos, afinal não existe relação entre faixa etária- seriação (ano escolar). A exigência para inscrição na EJA é a idade mínima de 15 anos para ingresso no ensino fundamental e de 18 anos para ensino médio (BRASIL, 2000). O que confere às turmas, desta modalidade, a pluralidade de fases de vida. Com isso, a prática docente deve estar inteiramente voltada a um público jovem e adulto, plural e trabalhador, diferente da prática pedagógica que acontece com a faixa etária da educação escolar

\footnotetext{
${ }^{1}$ De acordo com a Resolução CNE/CEB No 4, DE 13 DE JULHO DE 2010 que Define Diretrizes Curriculares Nacionais Gerais para a Educação Básica no capítulo II: a EJA é uma modalidade da Educação Básica e segundo o Artigo 28. "A Educação de Jovens e Adultos (EJA) destina-se aos que se situam na faixa etária superior à considerada própria, no nível de conclusão do Ensino Fundamental e do Ensino Médio.” (BRASIL, 2010, p. 09)
} 
obrigatória (7 aos 14 anos). Isto exige uma formação inicial diferenciada por parte dos cursos de licenciatura. Afinal, ser professor e professora na EJA é totalmente diferente de ser professor e professora na Educação infantil, e no ensino fundamental e médio.

De acordo com Arroyo (2006), a história da própria EJA está ligada a uma trajetória de luta, de busca pela escolarização que leve à emancipação e não à regulação, que é a educação que acontece nas modalidades regulares. Acreditamos então, em concordância com este autor, que a formação destes professores tem que ter uma especificidade que dê conta da realidade dos estudantes que frequentam esta modalidade de ensino. Acrescentamos ainda que a formação docente destinada a educação regular deve ser "contaminada" pela formação de professores que a EJA exige e necessita.

Acerca destas reflexões apresentadas, trazemos neste texto o mapeamento das produções acadêmicas que têm como objeto de estudo a Formação docente na modalidade da EJA, desenvolvido pelos autores que fazem parte do grupo de pesquisa do Laboratório de Estudos e Pesquisas de Educação em Geografia $\left(\right.$ LEPEGEO $^{2}$ ) em 2017. Tal reflexão partiu do desejo de compreender como se configura na contemporaneidade o contexto de formação de professores de EJA no Brasil. Para isso, buscamos no Banco de dissertações e teses da Capes trabalhos de 2015 e 2016 oriundos de Programas de Pós-Graduação em Educação em universidades brasileiras, com a área de concentração na Educação com os seguintes temas geradores: Formação continuada e Formação Docente na EJA. A busca com o uso dos descritos (formação de professores, formação docente e formação continuada) resultou em onze títulos de trabalhos, sendo que destes, nove foram pesquisas de mestrado e duas de doutorado.

Optamos por demarcar o recorte temporal de 2015-2016, pois Gonçalves (2015) realizou um balanço abordando a temática do período de 2000-2014. Este mapeamento de pesquisas caracteriza-se como uma amostra de produções realizadas e tem o intuito de, ainda que parcialmente, contribuir com as discussões que envolvem a Formação docente na EJA como campo de pesquisa e no processo de desenvolvimento e luta pela criação e implantação de políticas públicas e educacionais comprometidas com esta temática.

\footnotetext{
${ }^{2}$ Laboratório localizado na FAED/UDESC, coordenado pela professora Rosa Martins, está integrado ao grupo de pesquisa CNPQ - "Ensino de Geografia, formação docente e diferentes linguagens", que tem como foco investigar a formação inicial e continuada de professores de Geografia, como também, discutir temas pesquisados em trabalhos de conclusão de curso, de mestrado e doutorado desenvolvidos no Programa de PósGraduação em Educação da Universidade do Estado de Santa Catarina - FAED/UDESC e no Programa de PósGraduação em Geografia da Universidade Federal de Santa Catarina PPGEO.
} 
Diante do exposto, este texto está organizado em três partes. Para início de conversa nos detemos em discutir as principais categorias de formação inicial e formação continuada na modalidade da EJA. Junto a essa definição, discutimos as políticas públicas e educacionais e, principalmente, sobre os sujeitos que integram essa modalidade, sua trajetória e o seu amparo legal. Em sintonia com esta definição teórica, trazemos o processo de mapeamento das produções acadêmicas consultadas nos bancos de dados disponíveis no ciberespaço. E, por último, com os trabalhos analisados estabelecemos eixos de convergência entre eles que consideramos pertinentes para uma discussão e problematização de acordo com a abordagem que fazemos neste trabalho.

\section{Para pensar}

A Educação de Jovens e Adultos se expressa, atualmente, através de um aglomerado de desafios educativos e sociais que busca superar, em alguma medida, os problemas decorrentes das desigualdades socioeconômicas, geopolíticas e socioculturais que afetam a humanidade em escala global. Esta modalidade de ensino se constituiu com suas próprias políticas públicas e educacionais devido a intensos movimentos, debates e reivindicações daqueles que se uniram na causa em prol de uma educação emancipadora, conquistando um território e uma legislação que pode dar legitimidade a esta modalidade de ensino.

A resolução CNE/CEB N ${ }^{\circ}$ 1, de 05 de Julho de 2000 estabelece as Diretrizes Curriculares Nacionais para a EJA, pela qual em seu artigo $3^{\circ}$ trás que as Diretrizes Curriculares Nacionais para o Ensino Fundamental e as mesmas para o Ensino Médio se estendem para a correspondente etapa da EJA. No parágrafo único do Art. $5^{\circ}$ observamos as definições para a EJA enquanto modalidade destas etapas da Educação Básica,

[...] a identidade própria da Educação de Jovens e Adultos considerará as situações, os perfis dos estudantes, as faixas etárias e se pautará pelos princípios de equidade, diferença e proporcionalidade na apropriação e contextualização das diretrizes curriculares nacionais e na proposição de um modelo pedagógico próprio. (BRASIL, 2000, p. 2).

Consideramos que o princípio de equidade diz respeito a igualdade com aqueles sujeitos que concluíram as etapas do ensino regular "na idade própria”. Significa que o Estado valoriza que o estudante da EJA possa acessar o mesmo currículo para que obtenha nível de formação equiparado aos demais estudantes, de outra modalidade. O princípio da diferença se refere à distinção entre sujeitos da EJA em relação aos estudantes das demais modalidades de 
ensino da Educação Básica. Vale ressaltar que esse princípio é indispensável de compor o próprio currículo de formação dos professores que atuarão na EJA, pois na ação pedagógica e no cotidiano de sala de aula que muitos sujeitos se sentem desmotivados e excluídos deste espaço de reinserção, de inclusão na vida escolar. É por isto que a formação destes professores deve ser pautada em outro viés, que reconheça a importância das demandas destes estudantes que buscam a escola para dar continuidade a uma escolarização quer foi interrompida por diferentes motivos. Arroyo nos diz: "Costumo dizer que a formação do educador e da educadora de jovens e adultos sempre foi um pouco pelas bordas, nas próprias fronteiras onde estava acontecendo a EJA" (ARROYO, 2006, p. 17)

O princípio da proporcionalidade pretende garantir aos estudantes a possibilidade de se escolarizar em frente a tantos obstáculos. Trabalho, cuidado com filhos, com familiares adoecidos, dificuldades financeiras, esgotamento físico, mental, são algumas das diversas características presentes na vida destes sujeitos, que fazem jus a condições diferenciadas de acesso e permanência aos demais estudantes da escolarização básica. De acordo com Haas o perfil de estudante da EJA tem mudado nos últimos tempos. Existe uma gradativa mudança tanto pelo processo de juvenilização deste público, quanto por “incorporar cada vez mais excluídos, por razões diversas, da escola regular". (2013, p. 68)

A questão da formação de professores de EJA é então diferente sobremaneira da temática da formação de professores. Haja vista que a modalidade em discussão percorre um caminho bem distante da escolarização reguladora, em termos de objetivos, trajetória, sujeitos, movimentos, etc. A formação de professores de EJA, talvez por ser um campo ainda muito amplo e sem muitas definições possui contradições nas próprias legislações que se referem à Educação Básica e a formação de professores. Representa um campo político e social ainda complexo e que precisa de atenção e de avanço. Laffin (2012, p. 14) afirma que "ainda são poucas as instituições brasileiras que oferecem tal formação, ficando a mesma por conta da formação em serviço das redes de ensino". Considerando que apesar da importância da formação continuada, da autoformação, do professor pesquisador, a formação inicial é indispensável quando se pensa em um processo de educação legítimo destinado a sujeitos jovens e adultos.

Nas Diretrizes Curriculares Nacionais para EJA verificamos que "o preparo de um docente voltado para a EJA deve incluir, além das exigências formativas para todo e qualquer professor, aquelas relativas à complexidade diferencial desta modalidade de ensino". (BRASIL, 2000, p.56). Segundo Laffin (2012) a formação para EJA raramente se dá na 
graduação, mas em serviço, em aperfeiçoamento e em cursos de especialização. Ao se referir à pesquisa de Ribeiro (1999), a autora nos diz que o autor vem alertando para o fato dos estudos acadêmicos vêm denunciando "práticas de EJA que não correspondem às suas particularidades" (p.17).

Por isso, queremos destacar a importância desta temática para o meio acadêmico, ainda que não seja recente a discussão deste tema para quem destina sua atenção à EJA. Afinal, como se vê neste trabalho, não faltam referencias para denunciar a incipiência, a imaturidade e a ausência de atenção necessária nos cursos de formação docente para a EJA. Observamos que apesar das Diretrizes para EJA alertarem para a necessidade de formação específica e voltada para as particularidades desta modalidade, as práticas docentes que vem acontecendo não dão conta do que se considera relevante para aqueles sujeitos pertencentes ao grupo de estudantes da EJA. A simples transposição das modalidades do ensino fundamental e médio para uma modalidade de menor tempo esvazia todo sentido e luta da EJA.

Laffin (2012) chama atenção para a insuficiência dos conhecimentos que a academia tem produzido sobre as práticas e a formação docente de EJA. O que nos leva a refletir sobre a questão curricular dos cursos de licenciatura. É preciso dar maior visibilidade a temática no meio acadêmico, para que se conquiste um nível de consistência nas discussões e assim se amplie as possibilidades curriculares voltadas aos professores que pretendem atuar na EJA. Podemos pontuar aqui que a questão da fragilidade e precariedade presente nos cursos de formação de professores em relação a EJA pode resultar em uma atuação no mercado de trabalho também precária, que, associada a longas jornadas de trabalho, em diferentes escolas e também em diferentes modalidades, contribuem para tornar a profissão dos professores exaustiva e de baixa qualidade.

Braslavsky (2002) diz que o Brasil continua tendo um dos índices de desigualdade entre ricos e pobres mais elevados do mundo. O que nos leva a pensar que uma formação acadêmica abrangente e generalista para ser docente não dê conta do preparo profissional para atuar em tantas instâncias (educação infantil, ensino fundamental, médio, educação especial, tanto em lugares privilegiados social e economicamente, quanto nestas modalidades em regiões de periferia, e por ultimo na EJA, que é caracterizada por sujeitos trabalhadores).

Todo o referencial teórico trazido neste trabalho é unânime na defesa do que Althoff e Martins Filho (2016) trazem sobre o primeiro requisito para a garantia do direito à educação básica: "distinguir quem são os educandos de cada modalidade; saber sobre os tempos de vida (...)” (p.37). Isto porque o direito à educação básica não se garante unicamente pela lei, mas 
por todo um conjunto de ações que promovam a inclusão de todos em um território onde se promove educação de qualidade.

Consideramos a partir deste pressuposto, que a lei unicamente e exclusivamente não vem garantindo o direito à educação básica, afinal são inúmeros os excluídos da escola em faixa etária de escolarização obrigatória (sete aos quatorze anos). Ressaltamos aqui que excluídos não são apenas aqueles que evadem da escola no meio do processo, mas também aqueles que por repetências frequentes e regulares ultrapassam a faixa etária que obriga a escola a acolher e escolarizar aquele sujeito e então são encaminhados à EJA.

Acreditamos que devido à ausência da exigência na EJA de faixa etária corresponde à seriação (ano escolar), e da bagagem social e cultural ser mais forte que na infância, os sujeitos daquela modalidade são caracterizados, sobretudo, pela diversidade cultural. Tal característica acaba por exigir dos professores, do currículo, da coordenação, do material didático outra postura, outro discurso, e até mesmo outra seleção de conteúdos e metodologias. Ao tratar do perfil que constitui o território da EJA, Althoff e Martins Filho (2016) afirmam que o sujeito que busca a EJA é "diverso, heterogêneo e traz consigo uma bagagem de experiências de vida, com diversas identidades, necessidades, culturas e expectativas". (p.40). Desse modo o desafio está posto para o docente, fazendo com que ele reconheça essa diferença tanto física, cognitiva quanto linguística no processo de ensino aprendizagem. O conhecimento do docente sobre estas múltiplas especificidades deve fundamentar o planejamento das práticas pedagógicas que precisam ser coerentes, dialogadas e interativas com estes sujeitos.

Em sintonia com essa reflexão, Haddad (1992) diz que a busca pela escolaridade por jovens e adultos se dá como estratégia para sobreviver em uma sociedade onde o domínio do conhecimento ganha cada vez mais importância. Apesar deste artigo ter sido escrito no ano de 1992 (há 27 anos atrás) e a sociedade ter passado por profunda transformação no que se refere à fluidez informacional, acreditamos que o conhecimento continua sendo valorizado nas mais diversas instâncias sociais, sobretudo, na possibilidade de ascensão social através da escolarização, em outros termos, do domínio do conhecimento.

Arroyo (2006) diz que do mesmo modo que a EJA se constituiu, acontece a formação de educadores de EJA: pelas margens. Ele afirma que a formação de professores possui um caráter universalista, generalista que não se enquadra e nem deve se enquadrar no perfil de professores que a EJA necessita. "O perfil do educador de jovens e adultos e sua formação encontra-se ainda em construção". (p.18). Este mesmo autor declara que o perfil do docente 
que a EJA tem que ser um educador plural, múltiplo e multifacetado o que pressupõe que os cursos de formação de professores tenham o desafio de incorporar estes mesmos traços e especificidades em seus currículos. Isto não significa que docentes das demais modalidades não devam possuir estas características, pelo contrário, é fundamental que "esse perfil plural do educador de jovens e adultos contamine o perfil do educador escolar" (ARROYO, 2006, p. 20)

Este autor destaca que a atuação de professores sem formação específica para EJA com uma formação voltada para as modalidades da educação infantil, ensino fundamental e médio, pode caracterizar negligência e desrespeito as especificidades da EJA e sua importância social. A EJA não deve ser tratada do mesmo modo que outras modalidades, não apenas no aspecto do tratamento dado aos alunos adultos que não são crianças, mas em todos os aspectos curriculares.

O sistema educacional sempre foi mais regulador que emancipatório [...] Se queremos uma EJA emancipatória, dos jovens e adultos trabalhadores, populares, excluídos e oprimidos, será a melhor alternativa enquadrá-la no sistema educacional que tende a ser mais regulador? (ARROYO, 2006, p.21).

A partir de nosso referencial teórico podemos afirmar que os jovens e adultos da EJA não são quaisquer jovens e adultos, possuem particularidades de serem trabalhadores com trajetórias de luta, oriundos das periferias e do campo. Entretanto, sem desrespeitar a história e trajetória desta modalidade, nos desafiamos a pensar até que ponto este perfil de sujeitos é e seguirá o mesmo? Afinal, ainda reconhecemos a mesma escola de um século atrás, a mesma estrutura, o mesmo disciplinamento, o mesmo caráter industrial de linha de produção, de formação em massa de sujeitos sem diferença, sem diversidade, sem pluralidade cultural. Pensamos que a EJA, aquela defendida por nós, por Arroyo (2006), Althoff e Martins Filho (2016), Laffin (2012) e tantos outros autores, pode ser um território da educação emancipadora que a sociedade clama, mostrando assim que ela vem saldar uma dívida social que o país tem com os cidadãos, mas que é uma possibilidade de fuga de uma macroestrutura capitalista excludente, e que a escola pode se basear na proposta educativa da EJA.

\section{Para movimentar}

O mapeamento das produções acadêmicas identificadas no território virtual a partir dos descritos: Formação docente, formação de professores, Formação continuada e EJA, 
resultou em onze trabalhos com diferentes características, perfis e contextos geográficos (quadro 1). A partir da leitura dos resumos, sumários, referenciais teóricos e considerações finais, localizamos três eixos principais que atravessam os trabalhos: Formação docente, Formação continuada e Práticas pedagógicas infantilizadas, que foram alvo de análise e movimentação.

Quadro 1 - Característica dos trabalhos consultados

\begin{tabular}{|c|c|c|c|c|}
\hline$\underline{\operatorname{AUTOR}(\mathbf{A})}$ & TÍTULO & UNIVERSIDADE & CIDADE & $\frac{\text { NATUREZA/ }}{\underline{\text { ANO }}}$ \\
\hline $\begin{array}{l}\text { Kátia Maria } \\
\text { Silva } \\
\text { Gonçalves }\end{array}$ & $\begin{array}{l}\text { Estado do conhecimento sobre } \\
\text { formação de professores para } \\
\text { educação de jovens e adultos no } \\
\text { Brasil }(2000-2014)\end{array}$ & $\begin{array}{l}\text { Universidade } \\
\text { Cidade de São } \\
\text { Paulo }\end{array}$ & $\begin{array}{l}\text { São Paulo } \\
\text { SP }\end{array}$ & $\begin{array}{l}\text { Dissertação } \\
2015\end{array}$ \\
\hline $\begin{array}{l}\text { Adelson } \\
\text { Gomes da } \\
\text { Silva }\end{array}$ & $\begin{array}{l}\text { Professoras da eja: efeitos de } \\
\text { sentido dos discursos sobre a } \\
\text { formação continuada }\end{array}$ & $\begin{array}{c}\text { Universidade } \\
\text { Federal de Alagoas }\end{array}$ & $\begin{array}{c}\text { Maceió } \\
\text { AL }\end{array}$ & $\begin{array}{l}\text { Dissertação } \\
2015\end{array}$ \\
\hline $\begin{array}{l}\text { Ariadiny } \\
\text { Cândido } \\
\text { Morais }\end{array}$ & $\begin{array}{l}\text { Prática pedagógica e formação } \\
\text { dos professores da educação } \\
\text { profissional na relação com } \\
\text { concepções e princípios do } \\
\text { proeja }\end{array}$ & $\begin{array}{c}\text { Universidade } \\
\text { Federal de Goiás }\end{array}$ & $\begin{array}{l}\text { Goiânia } \\
\text { GO }\end{array}$ & $\begin{array}{l}\text { Dissertação } \\
2015\end{array}$ \\
\hline $\begin{array}{c}\text { Ranúsia } \\
\text { Pereira Silva }\end{array}$ & $\begin{array}{l}\text { Formação de professores para a } \\
\text { educação básica de jovens e } \\
\text { adultos: aproximações, teoria e } \\
\text { prática }\end{array}$ & $\begin{array}{l}\text { Universidade } \\
\text { Tiradentes }\end{array}$ & $\begin{array}{l}\text { Aracajú } \\
\text { SE }\end{array}$ & $\begin{array}{l}\text { Dissertação } \\
2015\end{array}$ \\
\hline $\begin{array}{l}\text { Alessandra } \\
\text { Fonseca } \\
\text { Farias }\end{array}$ & $\begin{array}{l}\text { O processo de formação inicial } \\
\text { de professores dos anos iniciais } \\
\text { da eja: uma análise do curso de } \\
\text { pedagogia de universidades } \\
\text { estaduais de São Paulo }\end{array}$ & $\begin{array}{l}\text { Universidade } \\
\text { Estadual Paulista } \\
\text { "Júlio de Mesquita } \\
\text { Filho" }\end{array}$ & $\begin{array}{l}\text { Presidente } \\
\text { Prudente } \\
\text { SP }\end{array}$ & $\begin{array}{l}\text { Dissertação } \\
2015\end{array}$ \\
\hline $\begin{array}{l}\text { Juliana } \\
\text { Bárbara } \\
\text { Camargo }\end{array}$ & $\begin{array}{l}\text { Formação de professores que } \\
\text { atuam num centro integrado de } \\
\text { educação de jovens e adultos } \\
\text { (cieja): as práticas cotidianas } \\
\text { como instrumento de formação }\end{array}$ & $\begin{array}{l}\text { Universidade } \\
\text { Cidade de São } \\
\text { Paulo }\end{array}$ & $\begin{array}{l}\text { São Paulo } \\
\text { SP }\end{array}$ & $\begin{array}{l}\text { Dissertação } \\
2015\end{array}$ \\
\hline $\begin{array}{l}\text { Luiz Renato } \\
\text { de Oliveira }\end{array}$ & $\begin{array}{l}\text { Ensinando e aprendendo com } \\
\text { projetos } \\
\text { temáticos: um desafio para a } \\
\text { formação } \\
\text { permanente de educadores da } \\
\text { educação } \\
\text { de jovens e adultos }\end{array}$ & $\begin{array}{c}\text { Universidade } \\
\text { Federal de Santa } \\
\text { Maria }\end{array}$ & $\begin{array}{l}\text { Santa } \\
\text { Maria } \\
\text { RS }\end{array}$ & $\begin{array}{l}\text { Dissertação } \\
2015\end{array}$ \\
\hline $\begin{array}{l}\text { Nisiael de } \\
\text { Oliveira } \\
\text { Kaufman }\end{array}$ & $\begin{array}{l}\text { A formação inicial de } \\
\text { professores das licenciaturas } \\
\text { para educação de jovens e } \\
\text { adultos no ensino médio: } \\
\text { desafios e possibilidades }\end{array}$ & $\begin{array}{c}\text { Universidade } \\
\text { Federal de Santa } \\
\text { Maria }\end{array}$ & $\begin{array}{l}\text { Santa } \\
\text { Maria } \\
\text { RS }\end{array}$ & $\begin{array}{l}\text { Dissertação } \\
2015\end{array}$ \\
\hline $\begin{array}{l}\text { Suzana } \\
\text { Andréia } \\
\text { Santos } \\
\text { Coutinho }\end{array}$ & $\begin{array}{l}\text { A formação continuada de } \\
\text { professores que atuam no proeja } \\
\text { no contexto do instituto federal } \\
\text { do maranhão (ifma) }\end{array}$ & $\begin{array}{l}\text { universidade federal } \\
\text { do maranhão }\end{array}$ & $\begin{array}{l}\text { São Luiz } \\
\text { MA }\end{array}$ & $\begin{array}{l}\text { Dissertação } \\
2015\end{array}$ \\
\hline $\begin{array}{l}\text { Poliana da } \\
\text { Silva Almeida }\end{array}$ & $\begin{array}{l}\text { Representações sociais de } \\
\text { professores da educação de }\end{array}$ & $\begin{array}{l}\text { Universidade } \\
\text { Estadual de }\end{array}$ & $\begin{array}{l}\text { Campinas } \\
\text { SP }\end{array}$ & $\begin{array}{l}\text { Tese } \\
2015\end{array}$ \\
\hline
\end{tabular}




\begin{tabular}{|c|c|c|c|c|}
\hline $\begin{array}{l}\text { Santos } \\
\text { Camargo }\end{array}$ & $\begin{array}{l}\text { jovens e adultos - eja sobre sua } \\
\text { formação docente e a } \\
\text { afetividade no processo de } \\
\text { ensino-Aprendizagem }\end{array}$ & Campinas & & \\
\hline $\begin{array}{l}\text { Rejane de } \\
\text { Oliveira } \\
\text { Alves }\end{array}$ & $\begin{array}{l}\text { Os inéditos-viáveis na e da } \\
\text { formação continuada de } \\
\text { professores que ensinam } \\
\text { matemática nos anos iniciais da } \\
\text { educação de jovens e adultos. }\end{array}$ & $\begin{array}{c}\text { Universidade de } \\
\text { Brasília }\end{array}$ & $\begin{array}{c}\text { Brasília } \\
\text { DF }\end{array}$ & $\begin{array}{l}\text { Tese } \\
2016\end{array}$ \\
\hline
\end{tabular}

Fonte dos dados: Banco de dissertações e teses da CAPES. Tabela produzida pelos autores.

Conforme dito anteriormente, realizamos a leitura da totalidade dos trabalhos e a partir daí estabelecemos três eixos de convergência entre eles que consideramos pertinentes à temática deste artigo. Seguimos então com a apresentação dos eixos, dos trabalhos a partir deste critério de classificação e das respectivas reflexões.

\section{Eixo 01: Formação Inicial}

O eixo formação inicial representou unanimidade dos trabalhos analisados: a carência da formação inicial voltada para EJA no contexto brasileiro. Para ilustrar esta afirmação trazemos alguns trabalhos com o intuito de melhor explanar esta questão. Para inicio de conversa, Farias (2016) verificou ao longo de sua pesquisa que o processo de formação inicial de professores dos anos Iniciais da EJA é previsto pelo Projeto Político Pedagógico de cursos das universidades de São Paulo, contudo de forma despretensiosa e contraditória, isto porque na maioria dos documentos há destaque para EJA como espaço de atuação do pedagogo, entretanto, a formação específica é contemplada em disciplinas optativas e que abordam o tema de maneira generalista, sem foco na instrumentalização pedagógica para a modalidade.

Em harmonia com o trabalho de Farias (2016), Alves (2016) em sua pesquisa concluiu que os conteúdos pedagógicos desenhados nas propostas curriculares dos cursos de pedagogia não dão conta de trazer aspectos importantes para o docente atuar com os estudantes da EJA. Essas linhas pontilhadas pelo autor nos levam a crer que tais peculiaridades formativas servirão como contrapeso no processo de ensino e aprendizagem dos sujeitos da EJA. Isto é, a falta de conhecimento sobre os aspectos legais e teóricos sobre essa modalidade no processo formativo baliza no chão da escola práticas educativas totalmente discordantes com o público que ali está.

Silva (2015) também percebeu em sua pesquisa que a política de formação dos professores da EJA no Brasil nunca foi dada a atenção devida ao tema da formação de 
professores para atuar na Educação de Jovens e Adultos, mesmo apontando alguns avanços, principalmente no campo legal, tais como o reconhecimento da EJA como modalidade de ensino da Educação Básica não se assumiu uma política de formação de professores que atendesse às especificidades desta modalidade de ensino.

As três pesquisas apresentadas neste momento evidenciam que a formação docente da EJA não é objeto de reflexão tanto política quanto epistemológica nos cursos de formação. Deste modo, os aspectos relacionados à teoria, aos conhecimentos, a legislação e as diretrizes, em detrimento do conhecimento dialogado, sistematizado e organizado possibilitou concluir que os cursos de formação inicial de professores não têm, em sua maioria, um currículo com previsão de disciplinas voltadas para EJA. Isso contribui para falta de profissionalização dos professores que atuam nesta modalidade de ensino, que acabam assumindo turmas sem estarem preparados para atuação num campo específico de trabalho, que é a EJA.

\section{Eixo 02: Práticas infantilizadas}

Neste eixo apresentamos o problema da infantilização decorrente de uma formação que não contempla os conhecimentos básicos dessa modalidade de ensino. Desse modo, esse problema acaba adentrando tanto nas propostas curriculares quanto na ação pedagógica.

Baseado neste pressuposto, Gonçalves (2015) ao analisar a questão da formação docente na modalidade da EJA explica que a formação inicial nesta modalidade de ensino encontra-se numa torrencial carência formativa. A autora percebeu que nas produções acadêmicas, que abarcou o levantamento de sua pesquisa de mestrado, que os cursos de pedagogia espalhados pelo território brasileiro não apresentam pressupostos teóricometodológicos suficientes para o docente trabalhar com a EJA. Os aspectos inerentes a formação tem tornado a qualidade das práticas pedagógicas inconsistentes, insignificantes, descontextualizadas e, principalmente, infantilizadas. Cabe acrescentar, também, que os trabalhos levantados pela autora indicaram que muitos dos professores que atuam em sala de aulas de EJA são oriundos de cursos de magistério ofertados pelo governo estadual e federal, que não tiveram na sua formação os conhecimentos específicos necessários para atuar nesta modalidade de ensino.

Morais (2015) estabelece uma relação entre o real e o ideal com os aspectos políticos e curriculares que desenham os documentos oficiais. De acordo com a autora, é possível inferir que o documento oficial se contrapõe à prática educativa. Levando assim a 
descontextualização e a infantilização dessas práticas e, sobretudo, a desvalorização do valor cultural, social, linguístico do sujeito presente na sala de aula. Quanto à concepção do real, seria justamente essa desarticulação, desalinhamento e encurtamento dos conteúdos escolares não relacionados com as características reais dos estudantes.

Morais (2015) faz uma crítica a problematização de como se dá a formação docente no território brasileiro. No entanto, o que se percebe hoje no processo de formação docente é que, os cursos estão camuflados de discursos e práticas mecanicistas, ideológicas, pragmáticas e tecnicistas. Predominando assim, uma formação ancorada numa visão produtivista, empreendedoras e utilitaristas, valorizando práticas ligadas aos caprichos do capitalismo. Isto é, o desenvolvimento de práticas formativas que visam o treinamento de mão de obra para determinada função no sistema produtivo. Numa direção oposta a essa proposta formativa, a autora afirma que a formação precisa estar amparada por uma relação verdadeiramente crítica a partir da dialética da ação e reflexão, ou seja, uma constituindo a outra em um processo ontológico e humanístico. Reverberando assim numa sólida formação tanto do professor quanto do estudante numa totalidade de determinações e relações estabelecidas socialmente, profissionalmente e geograficamente orientadas pela práxis pedagógica ${ }^{3}$.

A produção de Silva (2016) se atém em estudar se as propostas pedagógicas dos cursos de formação distribuídas de norte a sul do país para verificar se havia a preocupação em reservar em sua arquitetura curricular, disciplinas que discutam e fundamentem as particularidades da EJA na formação dos futuros docentes. No que tange a ausência de conteúdos que privilegiam essa modalidade de ensino a autora identificou em seu campo de estudos inúmeras situações de problemas didáticos e metodológicos recorrentes. Ou seja, atividades em sala de aula atribuindo conceitos obsoletos e infantis inadequados e/ou ineficazes para um público totalmente diferente. Levando a desmotivação, o desinteresse e, até mesmo, a desistência dos estudantes.

A pesquisa de Camargo (2015) com as demais produções pesquisadas mapeadas confirmou que no exercício da docência os processos, os métodos e os conteúdos são tramados por linhas infantilizadas, levando a desnaturalização do ensino e aprendizagem e, sobretudo, causando o desconforto e desinteresse dos estudantes dentro da sala de aula. O principal motivo desse problema, segundo autora, são as instituições formadoras que não se

\footnotetext{
${ }^{3}$ Entende-se a práxis como "a atividade concreta pela qual os sujeitos humanos se afirmam no mundo, modificando a realidade objetiva e, para poderem alterá-la, transformando-se a si mesmos. É a ação que, para se aprofundar de maneira mais consequente, precisa da reflexão, do autoquestionamento da teoria; e é a teoria que remete à ação, que enfrenta o desafio de verificar seus acertos e desacertos, cotejando-os com a prática" (KONDER, 1992, p. 115).
} 
preocupam em ofertar disciplinas obrigatórias ou optativas para que os egressos consigam sair das universidades preparadas para atuar nessa modalidade de ensino.

Farias (2016) alerta em relação à infantilização da EJA presente na própria infraestrutura do espaço escolar. Afirmando que

[...] há municípios brasileiros que não possuem estrutura física adequada para alunos adultos, porque aproveitam o período noturno de escolas municipais utilizando-se da mesma estrutura física. Assim, para além do campo pedagógico, em muitos municípios brasileiros a EJA se desenvolve com estrutura física imprópria para adultos, com carteiras e cadeiras pequenas, banheiros com vasos sanitários infantis e demais aspectos que foram planejados para crianças. (p.94)

A partir dos referenciais trazidos neste eixo podemos constatar em primeiro lugar que a formação de professores de EJA é deficitária no Brasil e entre as consequências negativas que acarreta pudemos ressaltar a infantilização deste público. Isso contribui para a desmotivação e evasão dos estudantes, que não tem acesso a uma educação compatível com sua faixa etária, com suas necessidades e seus anseios.

\section{Eixo 3: Formação continuada}

Este terceiro eixo que elencamos como um dos mais importantes dentro das analises realizadas está ligado a categorias como formação continuada, autoformação e formação em serviço. Isto porque uma prática reflexiva é essencial na autoformação do docente e representa um modo de formação em serviço.

A luz dessa premissa, Alves (2016) destaca que a concepção de formação continuada desponta de um conjunto de fatores associados à composição física, pedagógica, curricular da escola, ao investimento financeiro, à valorização e ao fomento à pesquisa e à divulgação dos conhecimentos construídos, que redimensionam a atuação docente em seu trabalho educativo. Baseado neste caldeirão de pressupostos e premissas formativas, a autora chama atenção que a formação continuada nestes tempos e espaços globalizados é essencial para que o docente consiga estrategicamente reinventar e ressignificar em sua ação pedagógica em situações de aprendizagem coerente e compatível com a cultura que a escola vem recebendo cotidianamente repleta de informações, novos costumes e formas de se expressar diferente.

Juntamente a estes elementos, a autora esclarece que a formação continuada deve estar respaldada, implementada e trabalhada a partir da partilha, do diálogo e da reflexão crítica no 
que tange a prática docente. Cabe ainda acrescentar à colocação da autora que o "Estado" junto à escola deve investir em situações de aprendizagem que orientem e estimulem os docentes a serem pesquisadores, tornando-os assim coadjuvantes e construtores de projetos, de trocas de experiências, de conhecimentos e reflexões no âmbito escolar. Tomando como eixo epistemológico a concepção de formação continuada como expressão na prática, a autora entende que a formação continuada deriva da relação afetiva e dialógica entre os pares que vive com o pé no chão da escola. E, ainda incluem num trabalho baseado na perspectiva dos inéditos-viáveis, isto é, o docente ser um investigador reflexivo e criador em seu campo de trabalho.

E, ainda neste mesmo gancho, Silva (2015) evidenciou que a formação continuada assume cada vez mais um formato compensatório, ou seja, voltado para subsidiar os professores sobre a prática pedagógica na EJA e suas especificidades, uma vez que a formação inicial vem deixando esta lacuna. Todavia, o autor mostra, claramente, que a verdadeira formação continuada é aquela que se constrói sobre a solidez de um movimento de atribuições e saberes específicos somados por ações, trocas e reflexões na própria ambiência da escola. Em sintonia com essa colocação, Kaufman (2015) sem desvalorizar a formação inicial, mas ressaltando a importância desta formação com um viés humanizado, afirma a importância da prática reflexiva,

É preciso que se ampliem os espaços de interação entre as dimensões pessoais e profissionais, uma vez que esta não se constrói por acumulação de técnicas, mas por meio de um trabalho de reflexão crítica sobre as práticas e de (re)construção permanente das mesmas. (p. 112)

Ancorado a essa discussão, Coutinho (2015) destaca o currículo como eixo fundamental para a educação, aqui voltado para a EJA e a formação docente. Ressalta neste aspecto a formação continuada, pois é a partir desta formação que os docentes desenvolvem suas ações pedagógicas de acordo com o que está estabelecido na proposta curricular da instituição, buscando fazer uma análise de sua prática regularmente, com o objetivo de melhorar e superar as dificuldades inerentes a ela. Para complementar a nossa interpretação, a autora adverte que,

[...] a qualificação do profissional docente não é adquirida somente por meio da formação inicial, mas por um processo constante de aprendizagem que permeia toda a sua prática educativa. Um dos espaços formadores de aprendizagem é a escola, considerada um instrumento fundamental nesse processo por estar permeada de subjetividades e por ser considerada lócus de 
diálogo, de experiência e consequentemente de reflexão da própria ação docente. (COUTINHO, 2015, p. 46)

De acordo com autora, é possível inferirmos que a válvula de escape para o profissional que vai atuar nessa modalidade de ensino é a formação continuada. Pois é a partir da fusão do calor da sala de aula com os conhecimentos trazidos pelos estudantes que o docente vai se constituindo e se formando cotidianamente em sua ação educativa.

Diante dessa realidade, Oliveira (2015) diz que em meio a tantas dificuldades que necessitam ser superadas no trabalho pedagógico, tanto por problemas pessoais dos estudantes, quanto na relação entre estes com os docentes, surge a possibilidade do que a autora chama de auto(trans)formação docente. Esta está ligada à formação permanente, em que professores buscam no dia-a-dia, na relação com os estudantes, construir e elaborar o conhecimento, de acordo com o interesse e a opinião da coletividade. Já Camargo (2015) foca sua atenção na formação que ocorre em serviço, pois considera que a formação inicial não promove o necessário preparo dos professores que trabalharão com a EJA.

A unanimidade da pesquisa entre os professores entrevistados ficou pela opinião de todos de que, a prática do dia a dia é que efetivamente constroem os seus saberes. É ali, enquanto estão com os alunos, com outros professores, nos momentos de reunião pedagógica, momentos de formação, que realizam a construção/aquisição dos seus saberes. (CAMARGO, 2015, p. 92)

Sendo o processo de formação inicial fragilizado, a autora cita que a formação continuada e o dia a dia em sala de aula como formas de superar essa lacuna. Concretamente, a autora cita que, a construção de habilidades de como lidar com os estudantes por meio das vivências, das interações, do diálogo, da troca de experiências com os pares da escola, das resoluções dos problemas corriqueiros e por iniciativa de pesquisas, por conta própria, em diferentes concepções, ajudam o docente dar conta de um processo de ensino aprendizagem compatível com os estudantes que constituem essa modalidade de ensino.

E, ainda nessa perspectiva, Gonçalves (2015) salienta que o processo de formação continuada ocorrido no espaço escolar é insuficiente e insignificante, pelo fato de serem ofertados treinamentos esporádicos, cursos aligeirados e programas de alfabetização sem continuidade. Sem se esgotar as possibilidades de questionamentos, a autora ressalta ainda decorrente da formação continuada o problema do preconceito que os docentes enfrentam tanto por parte da secretaria da educação quanto da própria escola, levando assim, a não proposições de propostas formativas no espaço escolar. Baseado nesse cenário, a autora destacou que a formação continuada deve estar alicerçada no tripé: ação, reflexão, ação. Essa 
perspectiva corresponde, em sua raiz, a um repertório de conhecimentos específicos que devem ser usados, operados e analisados sob situações que ocorrem por influencias dos conhecimentos tácitos.

Com base no que foi trazido neste eixo, percebemos que a formação inicial é fundamental apesar de não ser valorizada no contexto brasileiro, ainda é negligenciada. Por isto, a formação continuada, a prática reflexiva e a formação em serviço ganham um destaque maior do que já possuem. Ainda que a formação inicial fosse valorizada pelas políticas educacionais e pelas agências de fomento, não se diminui a importância e necessidade das demais formações em questão. Entretanto, visto a situação de incipiência em todo processo inicial de formação de professores da EJA, sobrecarrega-se os profissionais da educação para que se aperfeiçoem e qualifiquem, cobrindo lacunas estruturais.

\section{PARA NÃO FINALIZAR}

O trabalho aqui apresentado consistiu na análise das produções acadêmicas (do período de 2015-2016) mapeadas através do banco de dissertações e teses da CAPES, a partir dos descritos que compusessem os títulos dos mesmos: Formação docente, formação de professores, Formação continuada e EJA, o que resultou em onze trabalhos. Com a leitura dos resumos, sumários, referenciais teóricos e considerações finais, identificamos três eixos principais que atravessam as produções: Formação inicial, Formação continuada e Práticas pedagógicas infantilizadas, que foram alvo de análise e movimentação.

A partir de estudos e de reflexões trazidas na parte inicial deste artigo é possível reconhecer a fragilidade e imaturidade da formação docente no que se refere à EJA, justificando assim a relevância acadêmica desta temática, não apenas no âmbito da produção de conhecimentos, mas também na esfera política e substantiva do tema. Ou seja, é fundamental que ocorram movimentos no sentido de qualificar e emancipar a formação (seja ela inicial, continuada, etc.) para a atuação de professores na EJA.

A pesquisa bibliográfica realizada teve o intuito de encontrar subsídios para as reflexões trazidas. Buscamos identificar o que os trabalhos que lidam com a temática proposta trazem em comum a respeito da realidade concreta, cotidiana e política da formação de professores para a EJA.

Com a realização das pesquisas percebemos, em linhas gerais, que a formação docente na modalidade da EJA encontra-se entre o limbo da falta de qualificação adequada, coerente e 
própria e a escassez de formações continuadas no espaço escolar, reverberando assim, práticas pedagógicas inadequadas. Muitas das situações de formação continuada que acontecem na escola ocorrem de forma limitada, fragmentada, alienada e unilateral. Assim, o trabalho docente tolhido pelas fragilidades da formação, não possui sustentação em conhecimentos básicos para a atuação com a diversidade presente em uma sala de aula da EJA.

Notamos ainda que existem contradições inerentes às legislações em âmbito federal, como nas Diretrizes Curriculares Nacionais - DCN para Educação de Jovens e Adultos, e nos documentos que regem cursos de licenciatura e magistério distribuídos pelo país, resultado este trazido pelas pesquisas analisadas no levantamento. Isto porque as DCN afirmam a necessidade da formação docente voltada para as especificidades da EJA, enquanto nos currículos de graduações voltadas para formação inicial de professores privilegiam uma formação generalista e homogeneizadora das modalidades, abarcando a EJA apenas em disciplinas optativas.

Por último, ressaltamos a importância da prática pedagógica reflexiva concomitante com as concepções da formação em serviço, que valorizam ações docentes cotidianas comprometidas com a causa da educação de jovens e adultos trabalhadores que buscam nesta instância sua emancipação e melhores condições de vida.

\section{REFERÊNCIAS}

ALTHOF, F. , MARTINS FILHO, L. J. Mapeamento do estudante de ensino médio da Educação de Jovens e Adultos da rede estadual de ensino de Santa Catarina: cenários e perspectivas. In: Revista Brasileira de Educação de Jovens e Adultos. Vol. 4, nº 8, 2016.

ALVES, R. de O. Os inéditos-viáveis na e da formação continuada de professores que ensinam matemática nos anos iniciais da educação de jovens e adultos. Tese, Universidade de Brasília (UnB), Brasília - DF. 2016.

ARROYO, M. Formar educadoras e educadores de jovens e adultos. In: SOARES, L. (org.) Formação de educadores de jovens e adultos. Belo Horizonte: Autêntica/ SECADMEC/UNESCO, 2006.

BRASLAVSKY, C. Educação para todos para aprender a viver juntos: Um desafio prioritário no século XXI. In: BRASLAVSKY, C. (Org.). Aprender a viver juntos: educação para a integração na diversidade. Brasília: UNESCO, IBE, SESI,UnB, 2002.

BRASIL. Ministério da Educação. Conselho Nacional de Educação. Câmara de Educação Básica. Resolução n 1 , de 5 de julho de 2000. Estabelece as Diretrizes Curriculares Nacionais para a Educação e Jovens e Adultos. Brasília, 2000. 
CAMARGO, J. B. Formação de Professores que atuam num Centro Integrado de Educação de Jovens e Adultos (CIEJA): As práticas cotidianas como instrumento de formação. Dissertação, Universidade Cidade de São Paulo (UNICID), São Paulo - SP. 2015.

CAMARGO, P. da S. A. S. Representações sociais de professores da educação de jovens e adultos - EJA sobre sua formação docente e a afetividade no processo de ensinoaprendizagem. Tese, Universidade Estadual de Campinas (UNICAMP), Campinas - SP. 2015.

COUTINHO, S. A S. A formação continuidade de professores que atuam no proeja no contexto do instituto federal do maranhão (IFMA). Dissertação, Universidade Federal do Maranhão (UFMA), São Luiz - MA. 2015.

FARIAS, A. F. O. Processo de formação inicial de professores dos anos iniciais da EJA: uma análise do curso de pedagogia de universidades estaduais de são paulo. Dissertação, Universidade Estadual Paulista "Júlio de Mesquita Filho" (UNESP), Presidente Prudente- SP. 2016.

GONÇALVES, K. M. S. estado do conhecimento sobre formação de professores para educação de jovens e adultos no Brasil (2000 - 2014). Dissertação, Universidade da Cidade de São Paulo (UNICID), São Paulo - SP. 2015.

HAAS, C. Narrativas e percursos escolares de jovens e adultos com deficiência: "isso me lembra uma historia". Dissertação, Universidade Federal do Rio Grande do Sul (UFRGS), Porto Alegre - RS. 2013.

HADAD, S. Tendências atuais na Educação de Jovens e Adultos. In: Em aberto. Brasília, vol 11, no 56, out/dez. 1992.

KONDER, L. O futuro da filosofia da práxis: o pensamento de Marx no século XXI. 2 ed. Rio de Janeiro: Paz e Terra, 1992.

LAFFIN, M. H. L. F. Formação Docente para a Educação de Jovens e Adultos: sujeitos, diversidade e o mundo do trabalho. In: LAFFIN, M.H.L.F.(org.) Educação de Jovens e Adultos, Diversidade e o Mundo do Trabalho. Ijuí: UNIJUÍ, 2012.

MORAIS, A. C. Prática pedagógica e formação dos professores da educação profissional na relação com concepções e princípios do PROEJA. Dissertação, Universidade Federal de Goiás (UFG), Goiânia - GO. 2015.

KAUFMAN, N. de O. A formação inicial de professores das licenciaturas para educação de jovens e adultos no ensino médio: desafios e possibilidades. Dissertação, Universidade Federal de Santa Maria (UFSM), Santa Maria - RS. 2015.

OLIVEIRA, R. L. de. Ensinando e aprendendo com projetos temáticos: um desafio para a formação permanente de educadores da educação de jovens e adultos. Dissertação, Universidade Federal de Santa Maria (UFSM), Santa Maria - RS. 2015. 
SILVA, A. G. da. Professoras da EJA: efeitos de sentido dos discursos sobre a formação continuada. Dissertação, Universidade Federal de Alagoas (UFAL), Maceió - AL. 2015.

SILVA, R. P. Formação de professores para a educação básica de jovens e adultos: aproximações, teoria e prática. Dissertação, Universidade Tiradentes, Aracajú- SE. 2016.

\section{SOBRE OS AUTORES:}

\section{Suelen Santos Mauricio}

Doutorando em Educação na Universidade do Estado de Santa Catarina (UDESC) no Programa de Pós-Graduação em Educação na linha de Políticas Educacionais e Formação. Faz parte do grupo de pesquisa do Laboratório de Estudos e Pesquisas de Educação em Geografia (LEPEGEO) "Ensino de Geografia, formação docente e diferentes linguagens". Email: suelensmauricio@ hotmail.com

https://orcid.org/0000-0002-2128-8117

\section{Luiz Martins Junior}

Doutorando em Educação na Universidade do Estado de Santa Catarina (UDESC) no Programa de Pós-Graduação em Educação na linha de Políticas Educacionais e Formação. Faz parte do grupo de pesquisa do Laboratório de Estudos e Pesquisas de Educação em Geografia (LEPEGEO) “Ensino de Geografia, formação docente e diferentes linguagens”. Email: luizmartins.jr@hotmail.com

ORCID https://orcid.org/0000-0002-6026-8338

\section{Rosa Elisabete Militz Wypyczynski Martins}

Doutora em Geografia pela Universidade Federal do Rio Grande do Sul (UFRGS). Professora do Departamento de Geografia e no Programa de Pós-Graduação em Educação do Centro de Ciências Humanas e da Educação da Universidade do Estado de Santa Catarina (UDESC). Email: rosamilitzgeo@gmail.com

\section{https://orcid.org/0000-0002-2875-2883}

Recebido em: 09 de março de 2018 